\title{
Response to Letter to Executive Editor
}

\section{Thank you Dr. Asif.}

We really appreciate your observations, which indicate your depth of perusal through the published articles in BIRDEM Medical Journal.

In the first paper you mentioned, CTS was taken for the worse one and an advice is made that, optimum BMI attaining is beneficial. The paper describing fungal growth is rather thought provoking. It was contamination, not infection, which the authors stressed. Hypothyroidism (high TSH) is associated with dyslipidaemia. A research design can not be changed after it is done or new information may not be incorporated in a completed research, but the importance of changing colours of pills is praise worthy.

Thank you again for you inputs. It will help authors and editors.

\section{Khwaja Nazim Uddin}

Executive Editor

BIRDEM Medical Journal 